\title{
Retrospective and prospective measures of post-traumatic growth reflect different processes: longitudinal evidence of greater decline than growth following a hematopoietic stem-cell transplantation
}

\author{
Maya Corman ${ }^{1}$, Marie-Thérèse Rubio², Aurélie Cabrespine ${ }^{3}$, Isabelle Brindel ${ }^{4}$, Jacques-Olivier Bay ${ }^{3}$,
}

Régis Peffault De La Tour ${ }^{4}$ and Michaël Dambrun ${ }^{1 *}$

\begin{abstract}
Background: This prospective longitudinal study examined and compared two measures (prospective and retrospective ones) of post-traumatic growth (PTG) following Hematopoietic Stem-Cell Transplantation (HSCT) and their respective relationships with mental health and psychological disposition. We also tested the hypothesis that unwillingness to be in contact with distressing thoughts and feelings - -i.e. experiential avoidance - would moderate the relationship between PostTraumatic Stress Disorder (PTSD) and growth.

Methods: This study was carried out with 187 patients. Patients completed the Post-Traumatic Growth Inventory (PTGl) 5 months after HSCT and scales tapping into the five domains of PTGl during hospitalisation and 5 months after HSCT. Mental health and psychological disposition were also assessed prior to hospitalisation. A PTSD scale was administered at the five-month follow-up.

Results: Prospective and retrospective measures of PTG were weakly correlated. Bayesian pre/post-HSCT comparisons in the prospective measure of PTG revealed substantial to very strong decline in four of the five dimensions assessed. Overall, $\mathrm{RCI}$ indicated a reliable increase for $5.6 \%$ of patients and a reliable decrease for $40.8 \%$ of patients. Confirming that retrospective and prospective measures of PTG reflect different processes, they were not related to the same mental health and psychological disposition variables. Moreover, the hypothesis that acquiring positive outcomes from a potentially traumatic experience, such as $\mathrm{HSCT}$, requires direct confrontation with the source of distress was supported in the case of the retrospective measure of growth but not in the case of the prospective measure growth.
\end{abstract}

Conclusions: Retrospective measures such as the PTGI do not appear to assess actual pre- to post-HSCT change. HSCT seems more linked to psychological decline than to growth.

Keywords: Hematopoietic stem cell transplantation, Post-traumatic growth, Mental health, Psychological disposition, Post-traumatic stress disorder

\footnotetext{
* Correspondence: michael.dambrun@uca.fr

'Université Clermont Auvergne (UCA), LAPSCO CNRS, 34 avenue Carnot, 63037 Clermont-Ferrand, France

Full list of author information is available at the end of the article
}

(C) The Author(s). 2021 Open Access This article is licensed under a Creative Commons Attribution 4.0 International License, which permits use, sharing, adaptation, distribution and reproduction in any medium or format, as long as you give appropriate credit to the original author(s) and the source, provide a link to the Creative Commons licence, and indicate if changes were made. The images or other third party material in this article are included in the article's Creative Commons licence, unless indicated otherwise in a credit line to the material. If material is not included in the article's Creative Commons licence and your intended use is not permitted by statutory regulation or exceeds the permitted use, you will need to obtain permission directly from the copyright holder. To view a copy of this licence, visit http://creativecommons.org/licenses/by/4.0/ The Creative Commons Public Domain Dedication waiver (http://creativecommons.org/publicdomain/zero/1.0/) applies to the data made available in this article, unless otherwise stated in a credit line to the data. 


\section{Background}

Hematological malignancies and the side effects of treatments are particularly distressful and disturbing for the mental health and quality of life of patients $[1,2]$. Hematopoietic Stem Cell Transplantation (HSCT) is associated with fatigue, pain, anxiety, depression, and Post-Traumatic Stress Disorder (PTSD) [3-5]. However, several studies suggest that cancer and its treatment may be accompanied by a process of psychological recovery and growth. Some theorists even propose that growth requires the presence-and a direct confrontation with the source-of distress [6-8]. However, problematically, this area of research is subject to significant criticism and controversy, raising important issues not only about the nature of post-traumatic psychological growth following cancer and its treatment, but also about the processes involved [9-13].

Post-traumatic growth refers to a positive psychological change following a traumatic life event [8]. The Post-Traumatic Growth Inventory (PTGI) is the most commonly used instrument to assess growth following an adverse event [14]. However, it does not assess actual change but self-perceived growth. Numerous studies have highlighted the limitations of retrospective selfperceived measures such as the PTGI, which were recently summarised by Infurna and Jayawickreme [12] as follows: 'PTGI may reflect meaningful personality change to some degree but also maladaptive reality distortions, selective appraisals, coping strategies, personality characteristics, ways of explaining emotion levels, reflections of people's implicit theories of change, and beliefs that their past selves were worse than they actually were' (pp. 3-4). The Janus model proposed two components of PTGI: a constructive component and an illusory one [15]. The illusory nature of PTGI was empirically supported by the study by Frazier et al. [11], who concluded that this type of instrument does not appear to measure actual change. Furthermore, when comparing scores for actual change between before and after trauma, Frazier et al. did not find more evidence for reliable psychological growth than decline, raising issues about the characteristics of genuine post-traumatic growth and the best measure to describe it. This lack of robust empirical evidence, accompanied by significant methodological limitations, led Infurna and Jayawickreme [12] to recommend (a) caution when interpreting studies using retrospective self-perceived measures, and (b) the use of prospective longitudinal designs that allow a more reliable assessment of the change between before and after the adverse event. However, it is important to point out that pre/post-test designs also present some limits regarding the principles of response shift theory [16], which emphasises that changes in self-reported measures that occur over time can reflect a recalibration of internal standards of self-perception. Thus, we conducted a prospective longitudinal study among hematological cancer patients.

Studying post-traumatic growth in the case of cancer implies taking into account the specific circumstances related to this context. Sumalla et al. [17] indicate that cancer is a particularly aversive event and a number of characteristics need to be delineated. Among these, it may be difficult to identify a single stressor. There may be multiple stressors, including the diagnosis of the disease, its severity, the prognosis, the aggressiveness of treatment, etc. To limit confounding factors, we have only focused on HSCT in this study, and the participants were asked to give their feelings and thoughts only in reference to this aversive event. Thus, we conducted a prospective longitudinal study in which the primary purpose aimed to compare two methods of measuring posttraumatic growth using the same methodology as in Frazier et al.'s study (2009): a prospective one for actual growth and a retrospective one for perceived growth in the specific context of HSCT, a population underexplored about this issue. The secondary purpose aimed to put forward that both measures reveal different patterns of outcomes and distinct psychological correlates (mental health factors and psychological dispositions). Finally, to go further, we tested the hypothesis that acquiring positive outcomes from a traumatic event, such as HSCT, requires direct confrontation with the source of distress.

To compare retrospective and prospective measures of PTG, we drew inspiration from Frazier et al. [11]. Retrospective perception of growth was assessed with the PTGI at 5 months after HSCT. Prospective measure of growth was realised using scales that capture the five domains of growth assessed by the PTGI (i.e. relating to others, new possibilities, personal strength, spirituality change, and appreciation of life). Prospective measure of growth was done twice: during the week of the transplantation at the hospital and at the 5-month follow-up. We also examined the correlations between the five domains of retrospective and prospective measures of growth.

To go further in the study of the differences and similarities between both measures of PTG, we also studied their relationships with mental health and several psychological dispositions that we assessed 3 weeks prior to hospitalisation for HSCT. Concerning mental health, we selected anxiety, depression, and happiness. Concerning psychological dispositions, we selected optimism, acceptance, extraversion, and the five facets of dispositional mindfulness. According to the meta-analysis of Shand et al. [18], psychological growth following HSCT should be positively related to optimism and negatively related to poor mental health. In addition, recent research reveals that dispositional mindfulness and acceptance, a 
core construct of acceptance and commitment therapy, are beneficial psychological resources that could facilitate post-HSCT recovery $[19,20]$. Thus, we predicted that acceptance and dispositional mindfulness, especially the non-judging and non-reacting facets [21], would facilitate genuine growth measured prospectively.

Finally, we tested the prediction that post-traumatic growth requires direct confrontation with the source of trauma using both retrospective and prospective measures. In their meta-analysis, Shand et al. [18] found a small and positive relationship between PTSD and posttraumatic growth in cancer patients (i.e. $r=0.13$ ). We followed the rationale of Kashdan and Kane [22] in that unwillingness to be in contact with distressing thoughts and feelings-i.e. experiential avoidance-would moderate the relationship between Post-Traumatic Stress Disorder (PTSD) and growth. Thus, among patients who reported high experiential avoidance prior to HSCT, there should be no association between PTSD and psychological growth at the five-month follow-up. This association should appear only in patients with low experiential avoidance.

\section{Method}

\section{Participants}

The study protocol was presented to 275 patients. Of these, 236 signed the informed consent and entered in the 'psygreffe' cohort. Of these, 187 completed the first questionnaire $\left(M_{\text {age }}=52.07, S D=13.22\right.$, ranging from 19 to 72 years old), 157 filled out the second questionnaire, and 91 filled out the third questionnaire. ${ }^{1}$ Between the completion of the first and the third questionnaire, 30 participants died. In addition, 67 participants left the study during the protocol for various reasons (e.g. fatigue, lack of motivation) (Fig. 1). Patients came from three hospital centers of Paris, Nancy, and ClermontFerrand in France. Forty-one- point $9 \%$ of participants were female. In total, $65.7 \%$ were married, $46.3 \%$ had an

\footnotetext{
${ }^{1}$ We estimated the required sample size for sufficient statistical power using G*Power 3.1 (power $=80 \%$ ). First, concerning the comparison in prospective growth between time 1 and time 2, we selected 'Anova: Repeated measures, within factors' (Number of groups $=1$; Number of measurements $=2$; correlation among repeated measures $=0.5$ ) with a small effect size (i.e. Partial eta-squared $=0.05$, Effect size $\mathrm{f}=0.229$ ). The minimum required sample size was 52 . Second, on the basis of the correlation between coping and PTGI reported by Frazier et al. (2009; i.e. $r=0.52, r^{2}=0.27$ ), the minimum required sample size was 26. Finally, concerning the moderation hypothesis predicted based on Kashdan \& Kane (2011), we selected 'Linear multiple regression: Fixed model, $\mathrm{R}^{2}$ deviation from zero' (Number of predictors $=3$ ). Then, we specified predictor correlations using beta coefficients between predictors and outcome provided by Kashdan \& Kane in their Table 2 (2011; i.e. 0.04 for PTSD, 0.08 for experiential avoidance, and -0.35 for the interaction between PTSD and experiential avoidance). The obtained squared multiple correlation was 0.1293 and the effect size $f^{2}$ was 0.1485 . The minimum required sample size was 78 .
}

educational level beyond the license degree, and 22.5\% belonged to the upper-professional category. Seventeen percent had myelodysplastic syndrome, $10.4 \%$ had myeloproliferative neoplasia, and $35.7 \%$ were candidates for an allograft for acute leukemia. Ninety-four percent were having their first transplant (Table 1). In each hospital center, the patients interviewed could benefit from psychological support if needed. The ethical committee Sud-Est III (IRB 2017-026 B) approved the study. Informed written consent was obtained from each participant.

\section{Procedure}

All participants were informed of the study during the pre-graft interview (i.e. the doctor and medical staff give details about the allograft procedure, the expected benefits and related risks of the treatment, the functioning of the service, and so on) and read an information note. They had 15 days to decide whether they would participate or not. Then, they filled out an informed consent form and completed a first questionnaire assessing mental health (i.e. anxiety, depression, and happiness), psychological dispositions (i.e. optimism, extraversion, experiential avoidance, acceptance, and dispositional mindfulness) and sociodemographic variables (i.e. age, sex, marital status, and educational level) 20 days (Mean $=19.6, S D=14.14)$ before their hospitalisation for an allograft (Time 0). A second questionnaire was given at the start of hospitalisation and had to be completed during the first week from the day after the allograft intervention (Time 1). This second questionnaire evaluated five dimensions of post-traumatic growth, which constitute the prospective measure of growth. Finally, participants were invited to complete a third questionnaire at 5 months after their entrance to the hospital during a follow-up date (Time 2). This third questionnaire measured the same five domains of growth that constitute the prospective measure of growth, a scale measuring growth retrospectively (PTGI), and a measure of Post-Traumatic Stress Disorder (PTSD). The relevant medical data were extracted from the ProMISe (Project Manager Internet Server).

\section{Measures \\ Post-traumatic growth (PTG) assessment}

Retrospective measure of post-traumatic growth To assess perceived change from pre- to post-trauma, participants were asked to complete the Post Traumatic Growth Inventory (PTGI) [23] 5 months after the HSCT with regard to the transplant they had experienced. This scale measures post-traumatic growth across 21 items. Individuals are asked to indicate on a scale ranging from 0 ('I did not experience this change') to 5 ('I experienced 


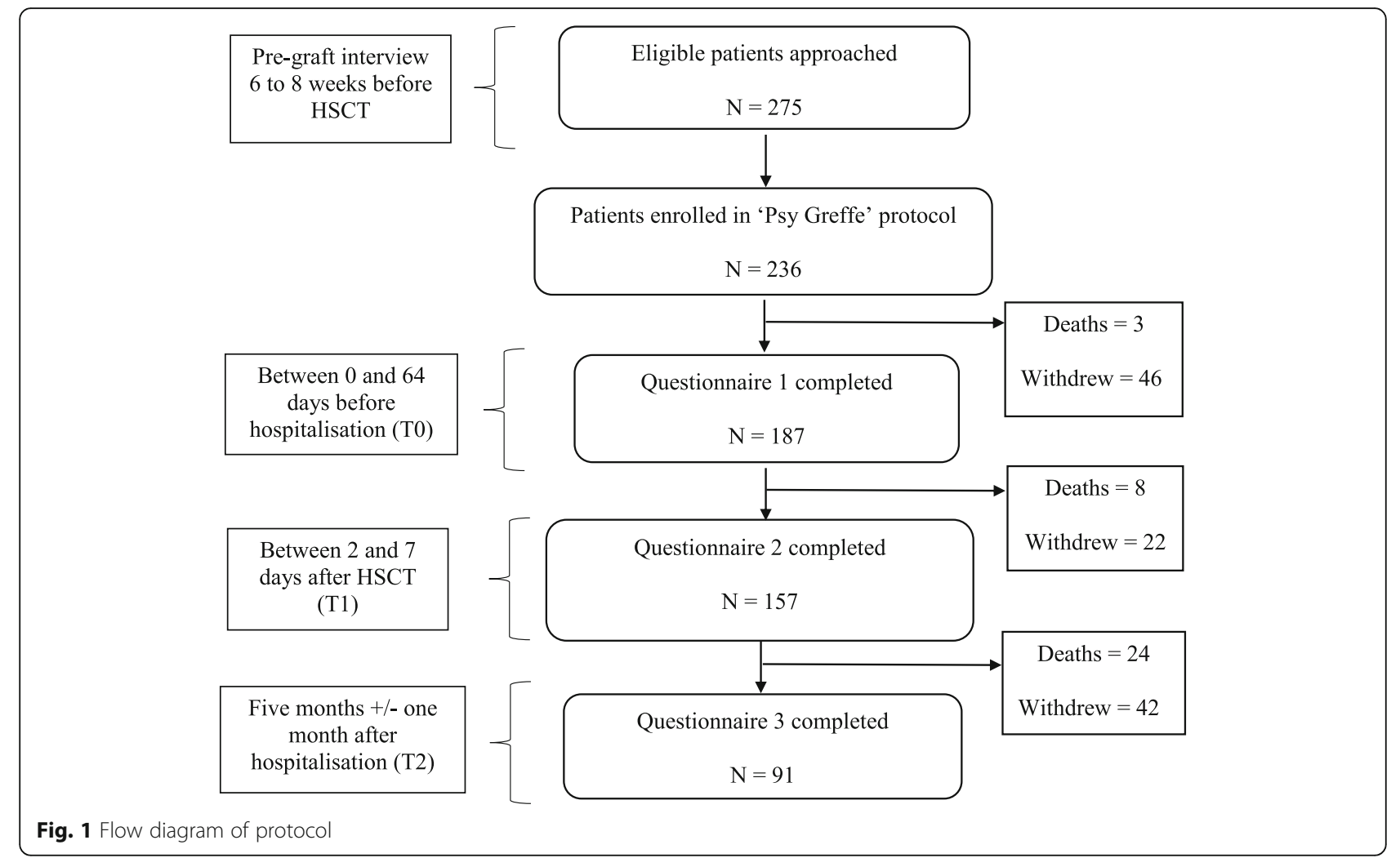

this change significantly') how much they experienced and lived with change in their life since HSCT. The total score is calculated by adding up each of the items. The internal consistency of the scale in our study is very satisfactory $(\alpha=0.96)$. The PTGI measures five areas of growth: (1) relating to others (e.g. 'I accept needing others') ( $\alpha=0.89$ ), (2) new possibilities (e.g. 'I developed new interests') $(\alpha=.90)$, (3) personal strength (e.g. 'I discovered that I'm stronger than I thought I was') ( $\alpha=$ $0.86),(4)$ spirituality change (e.g. 'I have a stronger religious faith') $(\alpha=0.78)$, and (5) appreciation of life (e.g. 'My priorities about what is important in life') $(\alpha=0.85)$.

Prospective measure of post-traumatic growth on measures of PTG dimensions To assess actual change from pre- to post-trauma, at both Time 1 and Time 2, we asked participants to complete several scales that corresponded to the dimensions of growth assessed by the PTGI. We examined whether the domain measures we chose assessed similar general constructs as the PTGI by correlating scores on the PTGI at Time 2 with scores on the five dimensions measured independently at Time 2. The first dimension, 'relating to others' was assessed using the 13-item Positive Orientation to Others dimension from the Goal and Mode Value Inventories [24] (e.g. 'Accepting others even though they may be different from you'; $\left.\alpha_{\mathrm{t} 1}=0.92 ; \alpha_{\mathrm{t} 2}=0.93\right)$. The correlation with 'relating to others' (PTGI) was $0.41(p<0.001)$. The second dimension, namely 'new possibilities', was assessed with the Personal Growth subscale (14 items) from Ryff and Essex's Psychological Well Being (PWB) scale [25] (e.g., 'I think it is important to have new experiences that challenge how you think about yourself and the world'; $\alpha_{\mathrm{t} 1}=0.79 ; \alpha_{\mathrm{t} 2}=0.79$ ). The correlation between this measure and the new possibilities dimension of PTGI was $0.28(p<0.01)$. The third domain, 'personal strength', was measured using the 24-item Brief Strengths Test, which is a brief version of the values in action inventory of strengths' (VIAIS) [26] (e.g. 'You are viewed as a creative person; you see, do, and/or create things that are of use; you think of unique ways to solve problems and be productive'). The 24-item scale had a satisfactory internal consistency $\left(\alpha_{\mathrm{t} 1}=0.86 ; \alpha_{\mathrm{t} 2}=0.92\right)$ and correlated positively with the 'personal strength' dimension of the PTGI $(r=0.29, p<0.01)$. The 24 personal strengths are grouped into six virtues (wisdom and knowledge, courage, humanity, justice, temperance, transcendence). The fourth dimension, 'change in spirituality', was assessed using the 6-item Intrinsic Spirituality scale of Hodge [27] (e.g. 'In terms of the questions I have about life, my spirituality answers no questions / absolutely all my questions'; $\alpha_{\mathrm{t} 1}=0.96 ; \alpha_{\mathrm{t} 2}=0.97$ ). This scale correlated strongly with the 'spirituality change' dimension of the PTGI $(r=0.60, p<0.001)$. Finally, 'appreciation of life', the fifth domain, was measured using the 5-item Satisfaction with Life Scale developed by Diener 
Table 1 Descriptive Statistics for Socio Demographic and Medical Variables at Time 0 and Time 2

\begin{tabular}{|c|c|c|c|c|c|c|}
\hline & \multicolumn{3}{|l|}{ Time 0} & \multicolumn{3}{|l|}{ Time 2} \\
\hline & $\%$ (excluding missing values) & Mean (SD) & $\mathbf{N}$ & $\%$ (excluding missing values) & Mean (SD) & $\mathbf{N}$ \\
\hline \multicolumn{7}{|l|}{ Controlled socio demographic variables } \\
\hline Age & & $52.03(13.28)$ & 217 & & $51.61(12.93)$ & 89 \\
\hline Sex (women) & 42.7 & & 221 & 42.7 & & 89 \\
\hline Marital Status (married) & 46.4 & & 181 & 48 & & 75 \\
\hline Educational Level (post-graduate) & 46.3 & & 175 & 46.1 & & 76 \\
\hline Socio-professional Category (employed) & 69.6 & & 151 & & 67.6 & 68 \\
\hline Follow-up (in months) & & $6.58(4.04)$ & & & & \\
\hline \multicolumn{7}{|l|}{ Controlled medical variables } \\
\hline Disease Status & & & 178 & & & 80 \\
\hline Acute Leukemia & 36 & & & 36.3 & & \\
\hline Myelodysplastic Syndrome & 17.4 & & & 13.8 & & \\
\hline Myeloproliferative Neoplasia & 10.1 & & & 8.8 & & \\
\hline Non-Hodgkin's Lymphoma & 11.8 & & & 13.8 & & \\
\hline Alcohol consumption (yes) & 30.8 & & 172 & 22.5 & & 71 \\
\hline Smoking (yes) & 15.8 & & 177 & 8 & & 75 \\
\hline Physical Activity (yes) & 45.3 & & 172 & 54.8 & & 73 \\
\hline Body Mass Index & & $24.92(4.61)$ & 176 & & $24.19(4.22)$ & 74 \\
\hline Sleeping hours & & $7.42(1.15)$ & 161 & & $7.29(1.15)$ & 68 \\
\hline Number of transplantations & & $1.07(0.3)$ & 178 & & $1.04(.19)$ & 80 \\
\hline Latency between disease & & $2.61(4.41)$ & 178 & & $3.03(4.69)$ & 80 \\
\hline \multicolumn{7}{|l|}{ diagnostic and transplantation (in years) } \\
\hline Myeloablative conditioning & 25.8 & & 178 & 25 & & 80 \\
\hline Chronic GvHD & 16.5 & & 164 & 18.1 & & 72 \\
\hline Donor type & & & 179 & & & 80 \\
\hline Identical sibling & 25.7 & & & 31.3 & & \\
\hline Mismatched unrelated & 8.9 & & & 8.8 & & \\
\hline Mismatched relative & 12.8 & & & 8.8 & & \\
\hline Matched unrelated & 38 & & & 41.3 & & \\
\hline Unrelated & 14 & & & 8.8 & & \\
\hline Matched other relative & 0.6 & & & 1.3 & & \\
\hline Latency engraftment (in days) & & $20.24(6.95)$ & 161 & & $19.85(5.67)$ & 73 \\
\hline Acute GvHD & 51.5 & & 171 & 57.9 & & 76 \\
\hline Relapse & 14.8 & & 162 & 5.6 & & 72 \\
\hline Number of infections & & $2.14(1.8)$ & 170 & & $1.87(1.82)$ & 76 \\
\hline Death & 16.4 & & 177 & 1.3 & & 80 \\
\hline
\end{tabular}

et al. [28] (e.g. 'In most ways my life is close to my ideal'; $\left.\alpha_{\mathrm{t} 1}=0.91 ; \alpha_{\mathrm{t} 2}=0.85\right)$. Unexpectedly, and contrary to Frazier et al. [11], this scale was not related significantly to the appreciation of life component from the PTGI $(r=0.12, p>0.25) \quad$ A composite score of prospective measure of PTG was computed by averaging the five dimensions. At Time 2, this composite score was positively and significantly related to PTGI $(r=0.42, p<0.001)$.

\section{Mental health and psychological disposition prior to hospitalisation Mental health}

We assessed anxiety, depression, and happiness. Anxiety and depression symptomatology was measured with the Hospital Anxiety and Depression scale (HADs) [29]. Seven items estimated anxiety symptomatology $\left(\alpha_{\mathrm{t} 0}=\right.$ $0.76 ; \alpha_{\mathrm{t} 2}=0.72$ ), and seven items assessed symptoms of 
depression $\left(\alpha_{\mathrm{t} 0}=0.70 ; \quad \alpha_{\mathrm{t} 2}=0.80\right)$. Happiness was assessed with the Subjective Authentic-Durable Happiness scale (SA-DHS) [30] $\left(\alpha_{\mathrm{t} 0}=0.96 ; \alpha_{\mathrm{t} 2}=0.97\right)$.

\section{Psychological dispositions}

While optimism was measured using the Life Orientation Test- revised (LOT-R; $\alpha=0.76$ ) [31], extraversion was assessed using the Big Five Inventory (BFI; $\alpha=0.84$ ) [32]. Experiential avoidance was measured with the Avoidance and Fusion Questionnaire for Adults (AFQ; $\alpha=0.88$ ) [33], and acceptance was assessed with the Acceptance and Action Questionnaire II (AAQ II; $\alpha=0.81$ ) [34]. Dispositional mindfulness was assessed with the FFMQ [35] $(\alpha=0.87)$. This scale comprises five dimensions: observing, describing, acting with awareness, nonjudging, and nonreactivity to the experience.

\section{PTSD assessment at follow-up}

The Post-Traumatic Stress Disorder Checklist Scale (PCLS) [36] was used to detect post-traumatic stress disorder through 17 items assessing the severity of 17 symptoms of PTSD listed in the DSM-V. This scale had an adequate internal consistency $(\alpha=0.91)$ (For all measures references see Supplementary File).

\section{Results}

Retrospective and prospective measures of growth

Table 2 presents descriptive data. Concerning the prospective measure of growth, we compared the scores obtained at the five-month follow-up with the scores assessed before HSCT. For each comparison, we reported the $p$-value and $\mathrm{BF}_{10}$ (i.e. the extent to which the data support $\mathrm{H}_{1}$ ). Substantial support for $\mathrm{H}_{1}$ was provided by a $\mathrm{BF}>3$ ( $\mathrm{BF}>10$ was judged strong; $>30$ very strong and $>100$ decisive). Support for $\mathrm{H}_{0}$ was provided by a $\mathrm{BF}<1$ [37].

Four of the five dimensions we measured showed a significant decrease between before and after transplantation (i.e. positive orientation, personal strengths, spirituality, and life satisfaction). Bayesian factors also provided clear support for the hypothesis of a decrease following HSCT for these four measures. The only dimension that did not vary significantly with time was the personal growth subscale from the psychological well-being scale [25]. The reliable change index (RCI) was computed for each dimension [38]. The percentage of reliable decrease was always superior to the percentage of reliable increase. The RCI for the mean score of change in growth indicated a

Table 2 Descriptive Data of Retrospective and Prospective Measures of Post-Traumatic Growth

\begin{tabular}{|c|c|c|c|c|c|c|}
\hline & $\begin{array}{l}\text { Mean before } \\
\text { HSCT }\end{array}$ & $\begin{array}{l}\text { Mean at 5-month follow- } \\
\text { up }\end{array}$ & $\begin{array}{l}\text { Change } \\
\text { score }\end{array}$ & $\mathrm{BF}_{10}$ & $\begin{array}{l}\text { Reliable } \\
\text { increase }\end{array}$ & $\begin{array}{l}\text { Reliable } \\
\text { decrease }\end{array}$ \\
\hline $\begin{array}{l}\text { Retrospective Measure of Growth } \\
\text { (PTGI) }\end{array}$ & - & & - & - & - & - \\
\hline - Relating to others & - & 2.90 & - & - & - & - \\
\hline - New Possibilities & - & 2.30 & - & - & - & - \\
\hline - Personal strength & - & 2.84 & - & - & - & - \\
\hline - Change in spirituality & - & 1.84 & - & - & - & - \\
\hline - Appreciation of life & - & 3.23 & - & - & - & - \\
\hline Mean score of PTGl & - & 2.67 & - & - & - & - \\
\hline \multicolumn{7}{|l|}{ Prospective Measure of Growth } \\
\hline - Positive orientation to others & 5.81 & 5.35 & $-0.46^{* * *}$ & 65 & $8.5 \%$ & $33.8 \%$ \\
\hline - Personal Growth subscale & 4.67 & 4.53 & $-0.14^{*}$ & 0.9 & $11.4 \%$ & $28.6 \%$ \\
\hline - Brief Strengths Inventory & 3.86 & 3.70 & $-0.16^{* *}$ & 7.8 & $10.0 \%$ & $28.6 \%$ \\
\hline Wisdom/knowledge & 3.87 & 3.70 & $-0.17^{* *}$ & 3.3 & $7.1 \%$ & $25.7 \%$ \\
\hline Courage & 3.85 & 3.79 & -0.06 & 0.2 & $10.3 \%$ & $10.3 \%$ \\
\hline Humanity & 4.03 & 3.84 & $-0.19^{*}$ & 2.5 & $10.3 \%$ & $27.9 \%$ \\
\hline Justice & 3.96 & 3.62 & $-0.34^{* * *}$ & 31.9 & $2.9 \%$ & $16.2 \%$ \\
\hline Temperance & 3.59 & 3.48 & -0.11 & 0.2 & $8.8 \%$ & $10.3 \%$ \\
\hline Transcendence & 3.92 & 3.76 & $-0.16^{*}$ & 0.9 & $8.8 \%$ & $17.6 \%$ \\
\hline - Intrinsic Spirituality scale & 4.80 & 4.16 & $-0.64^{* *}$ & 6.7 & $17.4 \%$ & $43.5 \%$ \\
\hline - Life satisfaction scale & 5.40 & 4.92 & $-0.48^{* * *}$ & 52.8 & $8.6 \%$ & $32.9 \%$ \\
\hline Mean score of growth & 4.90 & 4.52 & $-0.38^{* * *}$ & $\begin{array}{l}> \\
150\end{array}$ & $5.6 \%$ & $40.8 \%$ \\
\hline
\end{tabular}

*** $p<0.001,{ }^{* *} p<0.01,{ }^{*} p<0.05$ 
reliable increase for $5.6 \%$ of patients and a reliable decrease for $40.8 \%$ of patients.

\section{Relationship between retrospective and prospective measures of growth}

The mean score of change in growth (actual growth at Time 2 - actual growth at Time 1) was significantly and weakly related to the mean score of PTGI assessed at Time $2(r=0.25, p<0.036)$. As Table 3 shows, of the five dimensions in retrospective and prospective measures of growth assessed, two dimensions were significantly correlated (i.e. personal strengths and appreciation/satisfaction with life) and three domains were not significantly correlated (i.e. relating/positive orientation to others, new possibilities/personal growth subscale, and spirituality).

\section{Relationship between retrospective and prospective} measures of growth, and mental health and psychological dispositions

Table 4 presents the correlations between the measures of growth and those of mental health and psychological dispositions. Concerning mental health, while happiness prior to hospitalisation significantly predicted growth measured retrospectively $(r=0.36, p<0.001)$, change in growth measured prospectively was not significantly related to happiness $(r=0.14)$. Thus, the happiest patients prior to hospitalisation were those who perceived greater growth at the follow-up.

Extraversion prior to hospitalisation $(r=0.25, p<0.05)$, but not optimism and acceptance (respectively, $r=0.17$ and $r=0.06, p s>0.10$ ), was found to significantly and positively predict the PTGI. This was not the case with change in growth, measured prospectively, which was positively and significantly related only to acceptance $(r=0.39, p<0.01)$. Thus, the most extraverted patients prior to hospitalisation were those who reported the highest level of PTGI at the follow-up, and those who scored higher on the acceptance scale prior to hospitalisation benefited the most in terms of growth between transplantation and the five-month follow-up. Concerning dispositional mindfulness (see Table 5), observing and describing were significantly and positively related to the retrospective measure of growth (respectively, $r=$ 0.32 and $r=0.34$, $p s<0.01$ ), but not to the prospective measure of growth (respectively, $r=0.16$ and $r=0.23$, $p s>0.05)$. The nonjudgment facet was negatively and significantly related to the retrospective measure of growth $(r=-0.24, p<0.05)$ and positively and significantly related to change in growth $(r=0.28, p<0.05)$. The latter was positively and marginally related to nonreacting $(r=0.24, p<0.06)$, which was not the case with the retrospective measure of growth $(r=0.06)$.

Test of the moderating effect of experiential avoidance on the relationship between post-traumatic stress disorder (PTSD) and the retrospective/prospective measure of growth

We centred all the variables on the grand mean. Using Process Version 3.4.1. for SPSS, we performed a moderation analysis (Bootstrap: 5000 samples) [39] with PTSD as the independent variable, experiential avoidance as a moderator, and the retrospective measure of growth as a dependent variable (DV). While PTSD was marginally and positively related with growth when measured retrospectively $(\mathrm{b}=0.02, \mathrm{SE}=$ $0.01, p<0.06)$, experiential avoidance was not related to PTGI $(\mathrm{b}=0.14, \mathrm{SE}=0.22, p>0.50)$. We found support for a PTSD $\mathrm{x}$ experiential avoidance interaction effect in predicting post-traumatic growth measured retrospectively (PTGI; $\mathrm{b}=-0.03, \mathrm{SE}=0.01, p<0.038$ ). Conditioned at $1 \mathrm{SD}$ below the mean for experiential avoidance, PTSD was positively related to PTGI $(\mathrm{b}=$

Table 3 Correlations Between Retrospective Measure of Growth (PTGI) and Change in Growth (T2-T1)

\begin{tabular}{|c|c|c|c|c|c|}
\hline & \multicolumn{5}{|c|}{ Change in Growth (T2 - T1) } \\
\hline & $\begin{array}{l}\text { Positive orientation to } \\
\text { others }\end{array}$ & $\begin{array}{l}\text { Personal Growth } \\
\text { subscale }\end{array}$ & $\begin{array}{l}\text { Brief Strengths } \\
\text { Inventory }\end{array}$ & $\begin{array}{l}\text { Intrinsic Spirituality } \\
\text { scale }\end{array}$ & $\begin{array}{l}\text { Life satisfaction } \\
\text { scale }\end{array}$ \\
\hline \multicolumn{6}{|c|}{ Retrospective Measure of Growth at Time 2 (PTGI) } \\
\hline $\begin{array}{l}\text { Relating to } \\
\text { Others }\end{array}$ & 0.17 & 0.12 & $0.29^{*}$ & $0.20+$ & 0.10 \\
\hline New Possibilities & 0.15 & 0.16 & $0.29^{*}$ & 0.03 & 0.17 \\
\hline $\begin{array}{l}\text { Personal } \\
\text { Strength }\end{array}$ & 0.15 & 0.03 & $0.29^{*}$ & 0.07 & 0.17 \\
\hline Spiritual Change & 0.12 & $0.26^{*}$ & 0.03 & -0.01 & 0.09 \\
\hline $\begin{array}{l}\text { Appreciation of } \\
\text { life }\end{array}$ & 0.19 & 0.04 & $0.29^{*}$ & -0.05 & $0.25^{*}$ \\
\hline $\begin{array}{l}\text { Mean score of } \\
\text { PTGl }\end{array}$ & 0.18 & 0.13 & $0.29^{*}$ & 0.08 & 0.18 \\
\hline
\end{tabular}


Table 4 Prospective Effects of Mental Health and Positive Psychological Disposition Prior to Hospitalization for HSCT (Time 0) on Retrospective Measure of Growth (PTGl) at Time 2, and Change in Growth Between Time 1 and Time 2

\begin{tabular}{|c|c|c|c|c|c|c|}
\hline & $\begin{array}{l}\text { Anxiety } \\
\text { (HAD-A) }\end{array}$ & $\begin{array}{l}\text { Depression } \\
\text { (HAD-D) }\end{array}$ & $\begin{array}{l}\text { Happiness } \\
\text { (SA-DHS) }\end{array}$ & $\begin{array}{l}\text { Optimism } \\
\text { (LOT) }\end{array}$ & $\begin{array}{l}\text { Extraversion } \\
\text { (BFI) }\end{array}$ & $\begin{array}{l}\text { Acceptance } \\
\text { (AAQII) }\end{array}$ \\
\hline \multicolumn{7}{|c|}{ Retrospective Measure of Growth at Time 2 (PTGI) } \\
\hline Relating to Others & -0.05 & -0.11 & $0.42^{* * *}$ & $0.30^{* *}$ & $0.22+$ & 0.15 \\
\hline New Possibilities & 0.17 & 0.09 & $0.23^{*}+$ & -0.01 & 0.18 & -0.06 \\
\hline Personal Strength & -0.06 & -0.10 & $0.35^{* * *}$ & 0.13 & $0.23^{*}$ & $0.10+$ \\
\hline Spiritual Change & -0.01 & -0.07 & $0.23^{*}+$ & 0.13 & $0.19+$ & -0.02 \\
\hline Appreciation of life & 0.05 & -0.06 & $0.26^{*}$ & 0.15 & $0.32^{* *}$ & 0.09 \\
\hline Mean score of PTGl & 0.03 & -0.05 & $0.36^{* * *}$ & 0.17 & $0.25^{*}$ & $0.06+$ \\
\hline \multicolumn{7}{|l|}{ Change in Growth (Time 2 - Time 1) } \\
\hline Positive orientation to others & -0.17 & $-0.29^{*}$ & 0.21 & 0.03 & $0.24+$ & $0.22+$ \\
\hline Personal Growth subscale & $0.38^{* *}$ & 0.20 & $-0.23+$ & $-0.28^{*}$ & -0.06 & -0.09 \\
\hline Brief Strengths Inventory & -0.13 & -0.20 & 0.16 & 0.20 & $0.26^{*}$ & $0.50^{*}$ \\
\hline Intrinsic Spirituality scale & -0.07 & -0.20 & 0.11 & 0.15 & -0.18 & $0.24+$ \\
\hline Life satisfaction scale & -0.19 & 0.03 & 0.02 & 0.02 & 0.07 & 0.21 \\
\hline Mean score in growth change & -0.14 & -0.20 & 0.14 & 0.11 & 0.04 & $0.39^{* *}$ \\
\hline
\end{tabular}

*** $p<0.001,{ }^{* *} p<0.01,{ }^{*} p<0.05,+p<0.10$; A correlation with the retrospective measure of growth accompanied by + differs to 0.05 with the corresponding correlation with prospective measure of growth

$0.04, \mathrm{SE}=0.02, p<0.02)$, whereas when conditioned at 1 SD above the mean for experiential avoidance, PTSD was not related to PTGI $(b=0.01, S E=0.01$, $p>0.70)$. Thus, in the absence of experiential avoidance, PTSD was associated with greater perceived growth as assessed by PTGI. This was not the case in the presence of experiential avoidance. Finally, we computed a similar moderation analysis with the mean score of change in growth measured prospectively as a DV. Neither PTSD nor experiential avoidance were related to change in growth (all $p \mathrm{~s}>0.10$ ). We did not find support for a PTSD $\mathrm{x}$ experiential avoidance interaction effect $(b=-0.01, \mathrm{SE}=0.01, p>$ $0.45)$.

Table 5 Prospective Effects of Five Facets of Mindfulness Prior to Hospitalisation for HSCT (Time 0) on Retrospective Measure of Growth (PTGI) at Time 2 and Change in Growth Between Time 1 and Time 2

\begin{tabular}{|c|c|c|c|c|c|}
\hline & \multicolumn{5}{|c|}{ Five Facets Mindfulness Questionnaire (FFMQ) } \\
\hline & Observing & Describing & Acting with awareness & Non-reacting & Non-judging \\
\hline \multicolumn{6}{|c|}{ Retrospective Measure of Growth at Time 2 (PTGI) } \\
\hline Relating to Others & $0.30^{* *}$ & $0.33^{* *}$ & 0.13 & 0.16 & -0.11 \\
\hline New Possibilities & $0.28^{*}$ & $0.27^{*}$ & 0.08 & -0.04 & $-0.26^{*}+$ \\
\hline Personal Strength & $0.24^{*}$ & $0.28^{*}$ & $0.21+$ & 0.02 & $-0.17 \dagger$ \\
\hline Spiritual Change & $0.30^{* *}+$ & $0.22+$ & 0.05 & 0.08 & $-0.21+\dagger$ \\
\hline Appreciation of Life & $0.30^{* *}$ & $0.37^{* * *}$ & $0.26^{*}$ & 0.01 & $-0.29^{*}$ \\
\hline Total Score & $0.32^{* *}$ & $0.34^{* *}$ & 0.16 & 0.06 & $-0.24^{*} \dagger$ \\
\hline \multicolumn{6}{|l|}{ Change in Growth (Time 2 - Time 1) } \\
\hline Positive orientation to others & 0.21 & 0.19 & 0.22 & $0.26^{*}$ & 0.09 \\
\hline Personal Growth subscale & 0.05 & 0.11 & -0.15 & 0.04 & 0.14 \\
\hline Brief Strengths Inventory & $0.31^{*}$ & $0.29^{*}$ & 0.19 & 0.18 & $0.23+$ \\
\hline Intrinsic Spirituality scale & -0.06 & 0.01 & 0.14 & 0.17 & $0.24+$ \\
\hline Life satisfaction scale & 0.15 & 0.17 & 0.12 & -0.03 & 0.05 \\
\hline Mean score in growth change & 0.16 & $0.23+$ & $0.23+$ & $0.24+$ & $0.28^{*}$ \\
\hline
\end{tabular}

${ }^{* * *} p<0.001,{ }^{* *} p<0.01,{ }^{*} p<0.05,+p<0.10$; A correlation with the retrospective measure of growth accompanied by + differs by 0.05 with the corresponding correlation with prospective measure of growth 


\section{Discussion}

Focusing on post-traumatic growth among patients who have received an allograft, the primary aim of this study was to compare two methods of measuring posttraumatic growth: a prospective one for actual growth and a retrospective one for perceived growth in the case of HSCT. To address this primary aim, we compared scores on perceived post-traumatic growth, assessed by the Post-Traumatic Growth Inventory (PTGI) [8], and changes in scores of post-traumatic growth measured at two times (during the first week after transplantation and 5 months later) and corresponding to the five domains of PTGI. With a secondary objective, this research also aimed to highlight the different characteristics of retrospective and prospective measures of growth with respective relationships between these two measures of growth and both mental health and psychological dispositions, with a special investigation on dispositional mindfulness facets and experiential avoidance as a moderator between PTSD and both measures of growth.

Firstly, results seem to more support the hypothesis of decline rather than growth in the case of a prospective measure of post-traumatic growth 5 months after HSCT. These findings are consistent with the study of Frazier et al. [11], who found that post-traumatic growth, when assessed with a pre/post-test methodology is not as common as previously shown in numerous studies and can be a skewed perception of positive changes. More specifically, assessment instruments of post-traumatic growth, such as the PTGI-the most commonly used instrument to assess growth following an adverse event [14]-are not suitable for revealing a genuine decline or increase of growth. This suggests there is a need to develop more reliable instruments of post-traumatic growth [40] and conduct more systematic, longitudinal protocols, as recommended by Infurna and Jayawickreme [12]. In addition, the results of this study clearly raise questions about the specificities of the allograft process. Indeed, as highlighted by Sumalla et al. [17], research on posttraumatic growth should consider the substantial differences existing between the traumatic nature of cancer and an acute trauma, leading consequently to different health outcomes. For example, contrary to an acute stress, the temporal delimitation of the traumatic event in the case of cancer is not as perceptible or delimited for various reasons such as the risk of relapse. These differences have major implications on the lived experiences of patients who have to face an ongoing threat, which often engenders psychological distress. This observation is particularly true in the case of HSCT since patients are constantly confronted with the risk of relapse, infections, and graft versus host disease (GvHD) in the long-term, despite an improvement of patients' quality of life over time revealed by some studies. So, a decline in psychological growth could reflect the specificities of such treatments. It would be relevant to conduct a follow-up several years after HSCT to determine whether patients present a complete or a partial psychological recovery [41].

Other findings aimed at answering our secondary objective as revealed by this study include the weak correlation between retrospective and prospective measures of growth and the fact that they have different psychological correlates $[9,11]$. If growth assessed by PTGI is mainly related to positive thoughts and feelings such as happiness [18] and a personality trait (i.e. extraversion [23];), then growth measured prospectively is, however, only predicted by a characteristic of psychological flexibility, namely acceptance. The nature of psychological correlates of the retrospective measure of growth tends to support the interpretation of Infurna and Jayawickreme [12] who suggest that PTGI may reflect reality distortions, selective appraisals, coping, and personality characteristics. However, the prospective effect of acceptance on change in growth suggests the need to target preventively this dimension of psychological flexibility to alleviate psychological distress and enhance actual psychological growth among patients confronted with stressful events such as cancer [20] and HSCT.

Concerning dispositional mindfulness, with the exception of non-judging, most facets (i.e. observing, describing, acting with awareness, non-judging) did not robustly predict change in growth. This is not the case for the retrospective measure of growth, which is positively predicted by the observing and describing facets, whereas the non-judging dimension is negatively related to this measure of growth. These results seem to confirm that growth, when assessed retrospectively, is linked to a cognitive activity of interpreting lived experience that involves observing, describing, and judging one's inner experience, while change in growth is more related to decentering (here to non-judging) and acceptance processes.

The assumption made about the moderating effect of experiential avoidance on the relationship between PTSD and both measures of growth confirms the study of Kashdan and Kane [22] for retrospective measure of growth only. For the prospective measure of growth, this confirms the meta-analysis of Mangelsdorf et al. [13], who concluded that there is 'no general evidence for the widespread conviction that negative life events have a stronger effect than positive ones. Therefore, a direct confrontation with the source of distress does not allow for actual growth: it is rather its acceptance and lack of over-judging that seems important. On the other hand, as for Kashdan and Kane [22], this direct confrontation seems to be associated with retrospective perception of growth. This may once again depict the interpretive 
activity of lived experience. Those who are in avoidance do not interpret and do not positively re-evaluate their experiences. Consistently, research has revealed that avoidance coping is negatively related with positive reappraisal coping [42], the latter being involved in the perception of a post-traumatic growth [11].

\section{Conclusions}

To conclude the main results extracted from this study, we can observe, in the case of HSCT, a decline at 5 months when post-traumatic growth is measured prospectively, which suggests that a substantial portion of patients encounter impairments in their psychological state even a few months after the intervention. Therefore, it seems particularly relevant to identify post-HSTC difficulties that inhibit growth in order to remedy them. For example, future studies may examine the role of factors such as the consequences of transplantation (e.g. high risk of complications, physical and psychological sequelae) during the following months and years after transplantation $[4,5]$ or socio-demographic factors such age, which can influence the lived experience of posttraumatic growth. Despite the need for further studies with a more long-term follow-up and more suitable scales tapping into the five domains of the PostTraumatic Growth Inventory to characterise the nature of changes lived by patients, the prospective effect of acceptance and non-judging on actual growth offers an interesting perspective for prevention.

\section{Supplementary Information}

The online version contains supplementary material available at https://doi. org/10.1186/s12888-020-03007-y.

Additional file 1. Measures References

\section{Abbreviations}

HSCT: Hematopoietic Stem Cell Transplantation; PTSD: Post-Traumatic Stress Disorder; PTG: Post-Traumatic Growth; PTGI: Post-Traumatic Growth Inventory; RCl: Reliable Change Index; PWB: Psychological Well-Being; VIAI S: Values in Action Inventory of Strengths; HADs: Hospital Anxiety and Depression scale; SA-DHS: Subjective Authentic-Durable Happiness scale; LOT-R: Life Orientation Test-Revised; BFI: Big Five Inventory; AFQ: Avoidance and Fusion Questionnaire; AAQ: Acceptance and Action Questionnaire; FFMQ: Five Facets Mindfulness Questionnaire; PCLS: Post-Traumatic Stress Disorder Checklist Scale; BF: Bayesian Factor; DV: Dependant Variable; SD: Standard Deviation; GVHD: Graft Versus Host Disease

\section{Acknowledgements}

We would like to thank all the nursing staff and the clinical investigators of Saint-Louis Hospital, Nancy-Brabois Hospital and Estaing Hospital. We also thank promotor AGRAH and finally all the patients of EGMOS association.

\section{Authors' contributions}

All co-authors participated to the protocol conception, the acquisition of data, the paper writing and approved the submitted version of the manuscript. MC and MD developed the questionnaire, the general protocol, collected and treated the data, and wrote the paper. IB contributed to the compliance with ethical standards by the ethics considerations management during the protocol time and participated to the data collection. AC helped in the compliance with ethical standards, collected questionnaires in Estaing Hospital. MTR participated to the design of the work, the interpretation of data and served as coordinator for collection of questionnaires in NancyBrabois Hospital. JOB participated to the design of the work, the interpretation of data and served as coordinator for collection of questionnaires in Estaing Hospital. RPD contributed to the protocol development, the interpretation of data and served as coordinator in chief in Saint-Louis Hospital.

\section{Funding}

This study wasn't funded.

Availability of data and materials

Datasets of this study are available on https://doi.org/10.6084/m9.figshare. 12382916.v2

\section{Ethics approval and consent to participate}

This study was approved by the ethical committee Sud-Est III (IRB 2017-026 B)-Eastern Hospital Group, and registered in the Registry Clinical Trial under NCT03883672 (https://clinicaltrials.gov/). All patients provided written informed consent.

\section{Consent for publication}

Not applicable.

\section{Competing interests}

The authors declare that they have no competing interests.

\section{Author details}

${ }^{1}$ Université Clermont Auvergne (UCA), LAPSCO CNRS, 34 avenue Carnot, 63037 Clermont-Ferrand, France. ${ }^{2}$ Service d'hématologie, CHRU NancyHôpitaux de Brabois, 54511 Vandoeuvre-les-Nancy, France. ${ }^{3} \mathrm{CHU}$ de Clermont-Ferrand, site Estaing, service de thérapie cellulaire et d'hématologie clinique adulte, 63000 Clermont-Ferrand, France. ${ }^{4}$ Hôpital Saint-Louis, service d'hématologie, greffe de moelle, 75010 Paris, France.

Received: 16 July 2020 Accepted: 8 December 2020

Published online: 11 January 2021

\section{References}

1. Allart-Vorelli P, Porro B, Baguet F, Michel A, Cousson-Gélie F. Haematological cancer and quality of life: a systematic literature review. Blood Cancer J. 2015;5(4):e305

2. Linden W, Vodermaier A, MacKenzie R, Greig D. Anxiety and depression after cancer diagnosis: prevalence rates by cancer type, gender, and age. J Affect Disord. 2012:141(2-3):343-51.

3. Amler S, Sauerland MC, Deiters C, Büchner T, Schumacher A. Factors influencing life satisfaction in acute myeloid leukemia survivors following allogeneic stem cell transplantation: a cross-sectional study. Health Qual Life Outcomes. 2015;13(1):28.

4. Braamse AM, Gerrits MM, van Meijel B, Visser O, van Oppen P, Boenink AD, et al. Predictors of health-related quality of life in patients treated with autoand Allo-SCT for hematological malignancies. Bone Marrow Transplant. 2012;47(6):757-69.

5. Mosher CE, Redd WH, Rini CM, Burkhalter JE, DuHamel KN. Physical, psychological, and social sequelae following hematopoietic stem cell transplantation: a review of the literature. Psychooncology. 2009;18(2):113-27.

6. Affleck G, Tennen $\mathrm{H}$. Construing benefits from adversity: Adaptational significance and dispositional underpinnings. J Pers. 1996:64(4):899-922.

7. Davis CG, Nolen-Hoeksema S, Larson J. Making sense of loss and benefiting from the experience: two construals of meaning. J Pers Soc Psychol. 1998; 75:561-74.

8. Tedeschi RG, Calhoun LG. Posttraumatic growth: conceptual foundations and empirical evidence. Psychol Inq. 2004;15(1):1-18.

9. Boals A, Schuler K. Shattered cell phones, but not shattered lives: A comparison of reports of illusory posttraumatic growth on the Posttraumatic Growth Inventory and the Stress-Related Growth Scale-Revised. Psychol Trauma. 2019:11(2):239.

10. Coyne JC, Tennen H. Positive psychology in cancer care: bad science, exaggerated claims, and unproven medicine. Ann Behav Med. 2010;39(1): $16-26$. 
11. Frazier P, Tennen H, Gavian M, Park C, Tomich P, Tashiro T. Does selfreported posttraumatic growth reflect genuine positive change? Psychol Sci. 2009;20(7):912-9.

12. Infurna FJ, Jayawickreme E. Fixing the growth illusion: new directions for research in resilience and posttraumatic growth. Curr Dir Psychol Sci. 2019; 28(2):152-8.

13. Mangelsdorf J, Eid M, Luhmann M. Does growth require suffering? A systematic review and meta-analysis on genuine posttraumatic and postecstatic growth. Psychol Bull. 2019;145(3):302.

14. Jayawickreme E, Rivers J, Rauthmann JM. Do we know how adversity impacts human development? Res Hum Dev. 2018;15(3-4):294-316.

15. Zoellner T, Maercker A. Posttraumatic growth in clinical psychology-a critical review and introduction of a two component model. Clin Psychol Rev. 2006;26(5):626-53.

16. Howard JS, Mattacola CG, Howell DM, Lattermann C. Response shift theory: an application for health-related quality of life in rehabilitation research and practice. J Allied Health. 2011:40(1):31-8.

17. Sumalla EC, Ochoa C, Blanco I. Posttraumatic growth in cancer: reality or illusion? Clin Psychol Rev. 2009:29(1):24-33.

18. Shand LK, Cowlishaw S, Brooker JE, Burney S, Ricciardelli LA. Correlates of post-traumatic stress symptoms and growth in cancer patients: a systematic review and meta-analysis. Psycho-Oncology. 2015;24(6):624-34.

19. Garland EL, Thielking P, Thomas EA, Coombs M, White S, Lombardi J, Beck A. Linking dispositional mindfulness and positive psychological processes in cancer survivorship: a multivariate path analytic test of the mindfulness-tomeaning theory. Psychooncology. 2017;26(5):686-92.

20. Secinti E, Tometich DB, Johns SA, Mosher CE. The relationship between acceptance of cancer and distress: a meta-analytic review. Clin Psychol Rev. 2019;71:27-38

21. Larson AG, Morris KJ, Juckett MB, Coe CL, Broman AT, Costanzo ES. Mindfulness, experiential avoidance, and recovery from hematopoietic stem cell transplantation. Ann Behav Med. 2019;53(10):886-95.

22. Kashdan TB, Kane JQ. Post-traumatic distress and the presence of posttraumatic growth and meaning in life: experiential avoidance as a moderator. Personal Individ Differ. 2011;50(1):84-9.

23. Tedeschi RG, Calhoun LG. The posttraumatic growth inventory: measuring the positive legacy of trauma. J Trauma Stress. 1996;9(3):455-71.

24. Braithwaite VA, Law HG. Structure of human values: testing the adequacy of the Rokeach value survey. J Pers Soc Psychol. 1985;49(1):250.

25. Ryff CD, Essex MJ. The interpretation of life experience and well-being: the sample case of relocation. Psychol Aging. 1992;7(4):507.

26. McGrath RE. Technical report: the VIA assessment suite for adults: development and evaluation. Cincinnati, OH: VIA Institute on Character; 2017.

27. Hodge DR. The intrinsic spirituality scale: a new six-item instrument for assessing the salience of spirituality as a motivational construct. J Soc Serv Res. 2003;30(1):41-61.

28. Diener ED, Emmons RA, Larsen RJ, Griffin S. The satisfaction with life scale. J Pers Assess. 1985:49(1):71-5.

29. Zigmond AS, Snaith RP. The hospital anxiety and depression scale. Acta Psychiatr Scand. 1983;67(6):361-70.

30. Dambrun M, Desprès G, Lac G. Measuring happiness: from fluctuating happiness to authentic-durable happiness. Front Psychol. 2012;3:16.

31. Scheier MF, Carver CS, Bridges MW. Distinguishing optimism from neuroticism (and trait anxiety, self-mastery, and self-esteem): a reevaluation of the life orientation test. J Pers Soc Psychol. 1994;67(6):1063.

32. John OP, Srivastava S. The big five trait taxonomy: history, measurement, and theoretical perspectives. In: Handbook of personality: Theory and research, vol. 2; 1999. p. 102-38.

33. Fergus TA, Valentiner DP, Gillen MJ, Hiraoka R, Twohig MP, Abramowitz, et al. Assessing psychological inflexibility: The psychometric properties of the Avoidance and Fusion Questionnaire for Youth in two adult samples. Psychol Assess. 2012;24(2):402.

34. Bond FW, Hayes SC, Baer RA, Carpenter KM, Guenole N, Orcutt HK, et al. Preliminary psychometric properties of the acceptance and action questionnaire-Il: a revised measure of psychological inflexibility and experiential avoidance. Behav Ther. 2011:42(4):676-88.

35. Baer RA, Smith GT, Hopkins J, Krietemeyer J, Toney L. Using self-report assessment methods to explore facets of mindfulness. Assessment. 2006;13(1):27-45.

36. Weathers FW, Litz BT, Herman DS, Huska JA, Keane TM. The PTSD Checklist (PCL): Reliability, validity, and diagnostic utility. In: annual convention of the international society for traumatic stress studies, San Antonio, TX; 1993.
37. Jeffreys H. Theory of probability. 3rd ed. Oxford: Oxford University Press; 1961

38. Jacobson NS, Truax P. Clinical significance: a statistical approach to defining meaningful change in psychotherapy research 1992; 59 (1): 12-19.

39. Hayes AF. Introduction to mediation, moderation, and conditional process analysis: A regression-based approach. Guilford publications. ISBN 9781462534654; 2017

40. Boals A, Schuler KL. Reducing reports of illusory posttraumatic growth: A revised version of the Stress-Related Growth Scale (SRGS-R). Psychol Trauma. 2018:10(2):190.

41. Diener E, Lucas RE, Scollon CN. Beyond the hedonic treadmill: revising the adaptation theory of well-being. Am Psychol. 2006;61(4):305-14. https://doi. org/10.1037/0003-066X.61.4.305

42. Kvillemo P, Bränström R. Coping with breast cancer: a meta-analysis. PLoS One. 2014;9(11). https://doi.org/10.1371/journal.pone.011273.

\section{Publisher's Note}

Springer Nature remains neutral with regard to jurisdictional claims in published maps and institutional affiliations.
Ready to submit your research? Choose BMC and benefit from:

- fast, convenient online submission

- thorough peer review by experienced researchers in your field

- rapid publication on acceptance

- support for research data, including large and complex data types

- gold Open Access which fosters wider collaboration and increased citations

- maximum visibility for your research: over $100 \mathrm{M}$ website views per year

At $\mathrm{BMC}$, research is always in progress.

Learn more biomedcentral.com/submissions 